\title{
Parametric study on the effect of rainfall pattern to slope stability
}

\author{
Fathiyah Hakim Sagitaningrum ${ }^{1,}{ }^{*}$ and Erly Bahsan $^{1}$ \\ ${ }^{1}$ Department of Civil Engineering, Universitas Indonesia, Depok 16424, Indonesia
}

\begin{abstract}
Landslide in Indonesia usually occurs during the rainy seasons. Previous studies showed that rainfall infiltration has a great effect on the factor of safety (FS) of slopes. This research focused on the effect of rainfall pattern on the FS of unsaturated slope with different slope angle i.e.: $30^{\circ}, 45^{\circ}$, and $60^{\circ}$. Three different rainfall patterns, which are normal, advanced, and delayed were considered in the analysis. The effects of low or high hydraulic conductivity of the soil are also observed. The analyses were conducted with SEEP/W for the seepage and SLOPE/W for the slope stability. It is found that the lowest FS for gentle slope is reached under the application of advanced rainfall pattern and the lowest FS for steep slope is reached under the application of delayed rainfall pattern. Reduction of FS is known to be the largest for gentle slope rather than steep slope due to negative pore water pressure reduction and the rising of ground water level. The largest FS reduction caused by rainfall was achieved for gentle slope under advanced rainfall pattern.
\end{abstract}

\section{Introduction}

Slope stability failure in Indonesia usually occurs mainly during the rain. BNPB (National Board for Disaster Management) mentions that out of 493 landslides occurred in Indonesia in 2011-2014, 286 of them were caused short duration, high intensity rainfall, and long duration rainfall. The rainfall infiltrated the slope through soil cracks, saturating the soil and induced landslide or slope failure [1].

The rainfall infiltration cause the reduction in matric suction. As a factor of an increase in shear strength. The reduction of matric suction decrease the shear strength and reducing the stability of a slope [2-3].

The stability of slope usually represented by the factor of safety (FS) value. For example, [4] mention that FS $\geq 1.5$ can be used to represent that a slope is stable. On the contrary, FS $<1.5$ means that the slope will probably fail. Even though there is no such a unique correlation between the FS value and probability of failure [5], FS value is still favorable to predict the stability condition of slope by practical engineers.

This study will focus on the effect of different rainfall patterns to the factor of safety of slope. Nevertheless, the effect of slope's angle is also considered. Rainfall patterns will be taken form the higher five-days cumulative rainfall from Faculty of Engineering, Universitas Indonesia rain station from July 2014 until March 2015 data. The rainfall is then divided into three patterns, named normal, delayed, and advanced. Slope Geometry in this study is divided to three angles which are steep, gentle, and an angle between.
A finite element software from Geostudio, SEEP/W is used to analyse the effect of rainfall pattern to the groundwater level conditions. Another product from Geostudio, SLOPE/W, a limit equilibrium-based program, is used to analyse the factor of safety value of the slope regarding the groundwater conditions and the geometry of the slope.

The purpose of this study is to observed the effect of slope geometry and rainfall pattern to the slope's factor of safety and effect of pore water pressure change for slope's factor of safety.

\section{Theoretical overview}

\subsection{Unsaturated soil}

Unsaturated soil is a concept which stated that soil is not in a fully saturated condition. This concept explains that above the ground water level, the value of pore water pressure is not positive, but negative. The reason behind the negative value is due to the existence of matric suction where cohesion-adhesion reaction fills in between the soil particle because the void is filled with both air and water at the same time [3, 6-7].

Unsaturated soil consists of two components, which are matric suction and osmotic suction. While osmotic suction is a function of how many salts dissolved inside the soil void's fluid as pressure, matric suction is a deviation of air pressure inside the void with water pressure inside the void. This suction will then change the formulation of shear strength, seepage, and volume change of soil above the ground water level [7-8].

Corresponding author: fathiyah,hakim@gmail.com

C The Authors, published by EDP Sciences. This is an open access article distributed under the terms of the Creative Commons Attribution License 4.0 (http://creativecommons.org/licenses/by/4.0/). 
One of the distinct feature about unsaturated soil mechanics is the Soil-Water Characteristic Curve [9-10] which connects the function of volumetric water content and hydraulic conductivity with soil suction (matric suction).

\subsection{Infiltration}

Infiltration is related to rainfall, which usually defined as rainfall intensity $(\mathrm{mm} / \mathrm{hr})$. The factors that affect the infiltration rate are degree of saturation, compression of soil void, clogging void due to fine soils, vegetation, topography, and rainfall intensity [11].

Water will seep through soil and analysed as steadystate and unsteady-state, with the difference between the two analysis types is the change of hydraulic head and hydraulic conductivity because of time. Steady-state is an analysis which doesn't change through time and have a constant condition and vice versa for unsteady-state.

\subsection{Factor of safety of slope}

In slope stability typically factor of safety is formulated as the ratio between the resisting shear strength to the driving shear stress. In the unsaturated soil condition, the factor of safety can be written as [12]:

$$
\mathrm{F}_{\mathrm{s}}=\frac{\tau_{\mathrm{f}}}{\tau_{\mathrm{m}}}=\frac{\mathrm{c}^{\prime}+\left(\sigma-\mathrm{u}_{\mathrm{a}}\right) \tan \phi^{\prime}+\left(\mathrm{u}_{\mathrm{a}}-\mathrm{u}_{\mathrm{w}}\right)\left(\frac{\theta-\theta_{\mathrm{r}}}{\theta_{\mathrm{z}}-\theta_{\mathrm{r}}}\right) \tan \phi^{\mathrm{b}}}{\gamma_{\mathrm{t}} \mathrm{z}_{\mathrm{w}} \sin \alpha \cos \alpha}
$$

With $F s$ is the factor of safety, $\tau_{f}$ is the average shear strength, $\tau_{m}$ is the average shear strength with the potential to fail, $\alpha$ is the slope's angle, $z_{w}$ is the vertical depth of unsaturated soil, $\gamma_{t}$ is the unit weight of the soil, $c^{\prime}$ is the cohesion, $\sigma$ is the total normal pressure, $\left(\sigma-u_{a}\right)$ is the effective normal pressure, $\varnothing^{\prime}$ is the effective friction angle, and $\varnothing_{b}$ is the increasing friction angle due to the presence of matric suction.

\subsection{Related studies}

To know the differences between this study and the previous ones, a parametric study from [2] is taken as a reference. The study focuses on a typical Singapore slope geometry behaviour at three different rainfall patterns (normal, advanced, and delayed) at two different conductivity value, Low $\left(1 \times 10^{-6} \mathrm{~m} / \mathrm{s}\right)$ and High $\left(1 \times 10^{-}\right.$ ${ }^{5} \mathrm{~m} / \mathrm{s}$ ).

At Low Conductivity (LC), the greatest reduction of FS is achieved at advanced pattern with the average of all patterns reduction about $40-45 \%$ from the initial FS. Different results shown at High Conductivity (HC) with the average reduction of $10-13 \%$ and the greatest reduction is achieved at delayed pattern. It is also known from this research that FS reduction is caused by increasing value of pore water pressure which decrease matric suction and rising ground-water level.

\section{Research method}

\subsection{Soil parameters and slope geometry}

The soil material in this study is taken to be a homogeny silty clay layer in an unsaturated condition of $80 \%$ water content. The parameters of the soil are assumed based on some literatures [13-14], shown in Table 1.

Table 1. Silty clay soil properties

\begin{tabular}{|c|c|}
\hline Soil type & Silty clay \\
\hline$\gamma_{\text {sat }}\left(\mathrm{kN} / \mathrm{m}^{3}\right)$ & 18 \\
\hline$\gamma_{\mathrm{d}}\left(\mathrm{kN} / \mathrm{m}^{3}\right)$ & 15 \\
\hline $\mathrm{c}\left(\mathrm{kN} / \mathrm{m}^{3}\right)$ & 25 \\
\hline$\varphi\left({ }^{\circ}\right)$ & 20 \\
\hline Water content & $70-80 \%$ \\
\hline $\mathrm{K}_{\mathrm{sat}}(\mathrm{m} / \mathrm{s})$ & $10^{-6}$ \\
\hline
\end{tabular}

The soil is at an unsaturated condition, which in $\mathrm{SEEP} / \mathrm{W}$, needed to input the property of volumetric water content and hydraulic conductivity function for matric suction. The function used in SEEP/W is Fredlund-Xing estimation from Silty Clay material inside SEEP/W itself. Without any residual water content, the relationship between volumetric water content and hydraulic conductivity with matric suction is as Fig.1.
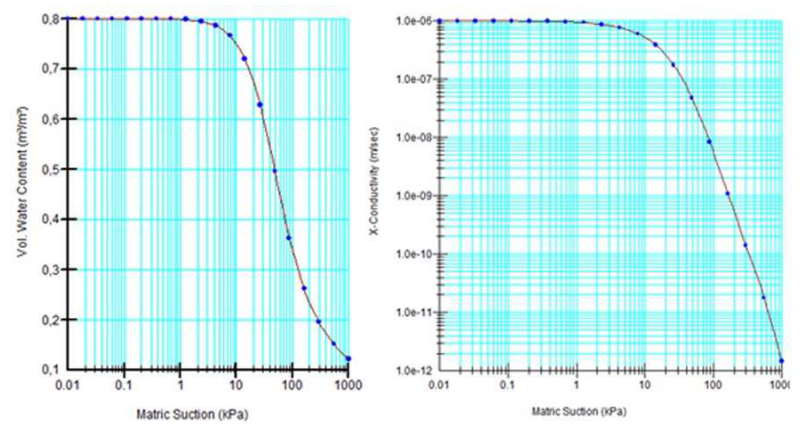

Fig. 1. Volumetric water content and hydraulic conductivity versus matric suction function SEEP/W

The slope height is taken to be 10 meters. The ground water level is assumed to be at the elevation of the slope's foot and the bedrock is at the elevation of 3 times the height under the slope's foot elevation, which is 30 meters under the slope's foot elevation. The geometry of the slope is varied by the slope's angle, which are $60^{\circ}$ that represent the steep slope, $30^{\circ}$ as the gentle slope, and the $45^{\circ}$ consider as the in between.

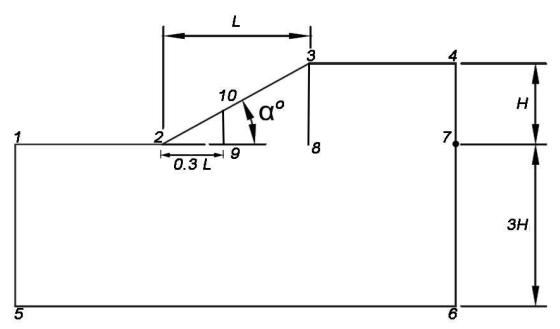

Fig. 2. Slope geometry 


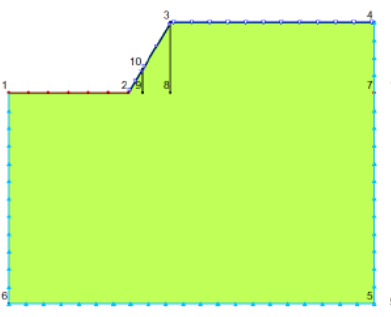

(a)

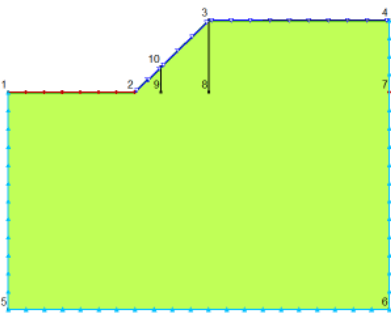

(b)

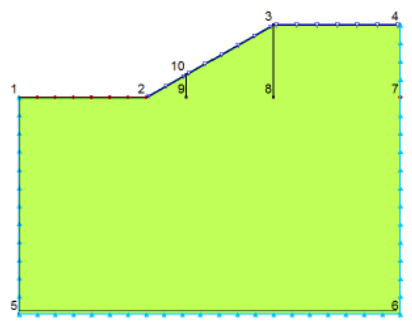

(c)

Fig. 3. Slope model for (a) $60^{\circ}$, (b) $45^{\circ}$, and (c) $30^{\circ}$ angles

\subsection{Boundary conditions}

The geometry and soil property is then applied to the program. For SEEP/W, there are two types of boundary condition. From Fig.2, there are several boundary conditions applied for steady-state analysis in order to achieve the initial condition of the slope, which are the 1-5-6-7-4 line as the zero total flux that shows no water that will flow through the boundary, the 2-10-3-4 line as the unit flux boundary with potential seepage review so that the pore water pressure at the surface will stay as zero throughout the analysis to avoid any ponding when the rain falls at the transient analysis, and line 1-2 and point 7 as the zero pore water pressure boundary that shows the elevation of the ground water level. For the transient analysis, the boundary conditions are only the unit flux boundary and zero pore water pressure boundary because the initial condition for the slope is sustained throughout the analysis from the result of the steady-state analysis.

As for the SLOPE/W, the analysis taken is Bishop analysis with the entry-exit method boundary condition.

\subsection{Rainfall parameters}

The rainfall pattern parameter is taken from Faculty of Engineering, Universitas Indonesia rain station from the period of July 2014 - March 2015. From all the data taken at the period, the hourly rainfall for the month is then divided into five-days rainfall. This is according [2] and the data of the rain station which provides a 5-day rainfall occurring at one of the month.

The 5-days rainfall then divided into 15 intervals. The number of intervals taken because an interval with long duration of rainfall will make the rainfall intensity too small that would make it hard to differentiate the rainfall patterns. On the contrary, if the interval time is too short, the rainfall pattern will be too much so that it would be hard to categorize. The rainfall patterns are taken from January 2015's rainfall. The total rainfall from each of the interval is then divided by the total rainfall of the 5-days rainfall to get the percentage of every interval.

From the actual percentage of each interval, idealization is made from random numbers generated so that the patterns which is like normal distribution is called normal, while the other two patterns which are like normal distribution with skewness are called delayed and advanced that were differentiate by the top of the intensity. The idealized percentage is then multiplied by the total 5-days rainfall in November 2014 with the total intensity of $225 \mathrm{~mm}$. This value is used because the 5-days rainfall intensity in January 2015 is not as high as the 5-days rainfall intensity in November 2014. From the value, there are three rainfall patterns as shown in Fig. 4.
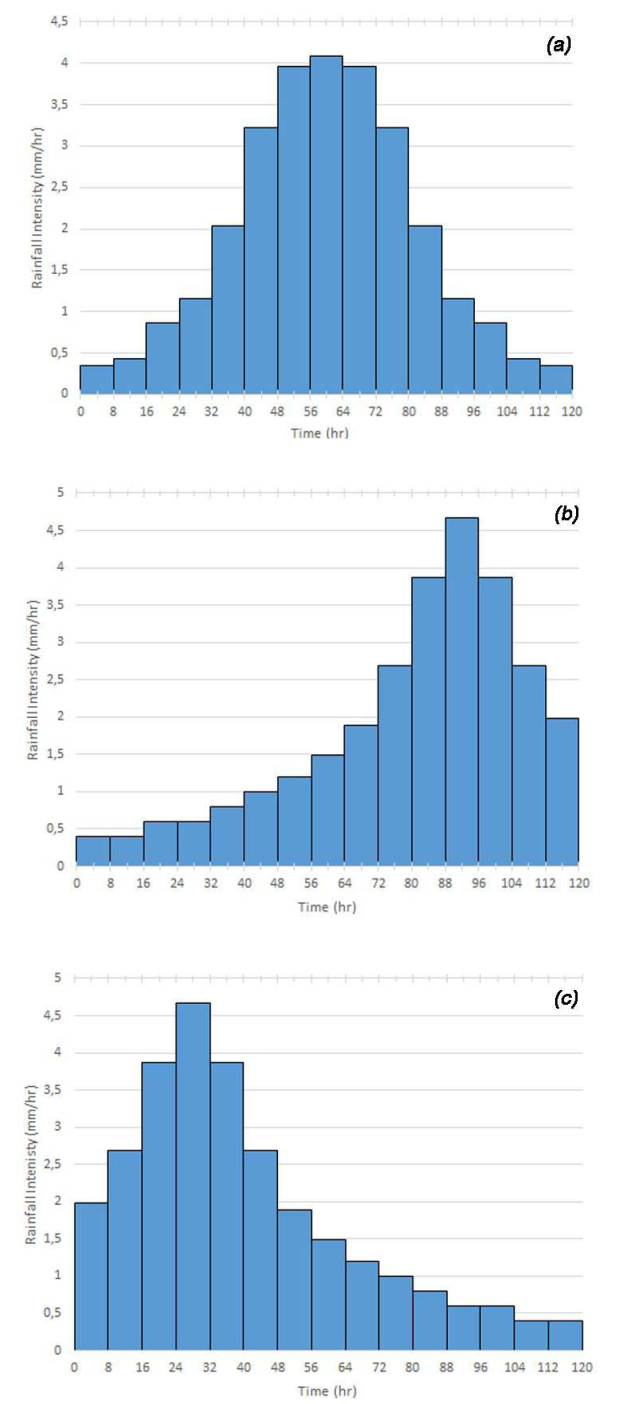

Fig. 4. Rainfall patterns (a) normal, (b) delayed, and (c) advanced

\subsection{Scenarios}

There are two scenarios conducted in this study are shown in Fig. 5. 


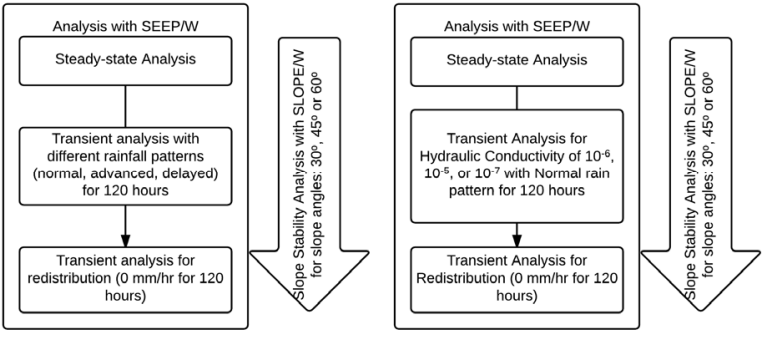

Fig. 5. Scenarios (a) Differentiates rainfall pattern and (b) Differentiates hydraulic conductivity value

The first scenario (Fig.5a) shows that the first analysis is a steady-state analysis with SEEP/W, which is a steady analysis that doesn't change through time so that the initial condition of the slope can be obtained. After that, the rainfall is applied to the slope for 120 hours for each of the rainfall patterns; normal, delayed, and advanced with transient analysis that can change the pore water pressure's profile through time and obtained different behaviour for every rainfall patterns applied. Lastly, the slope is applied to a redistribution step with transient analysis that doesn't have any rainfall for 120 hours to distribute the infiltrated water evenly throughout the slope. Every step of analysis performed is accompanied by SLOPE/W analysis to know the FS of each of the conditions and applied to each of the angles; $30^{\circ}, 45^{\circ}$, and $60^{\circ}$.

The second scenario (Fig.5b) is almost the same as the first, but the rainfall pattern used in this scenario is the normal rainfall pattern with the variation is the hydraulic conductivity of the soil, which are differentiate as $10^{-6} \mathrm{~m} / \mathrm{s}, 10^{-5} \mathrm{~m} / \mathrm{s}$, and $10^{-7} \mathrm{~m} / \mathrm{s}$ to analyse the effect of different hydraulic conductivity for the change in FS.

\section{Results and discussion}

The results obtained from SEEP/W and SLOPE/W for each case are then compiled for three different discussions.

\subsection{The effect of rainfall pattern to FS for different slope angles}

With different rainfall patterns, such as normal, advanced, and delayed for different slope angles, which are $30^{\circ}, 45^{\circ}$, and $60^{\circ}$, the results are shown in Fig.6.

From Fig.6, it is shown that the initial FS value for each slope is 2.111 for $30^{\circ}, 1.898$ for $45^{\circ}$, and 1.850 for $60^{\circ}$. From Fig.6a and Fig.6b, it is shown that for angle $30^{\circ}$ and $45^{\circ}$, the smallest FS is achieved at advanced pattern with the value of 2.085 for $30^{\circ}$ and 1.883 for $45^{\circ}$. As for $60^{\circ}$ angle, the smallest FS is achieved at delayed pattern with the value of 1.828 .

From Fig.6, it is also shown that FS reduction has the same pattern as the location of peak intensity of each rainfall pattern. For example, the advanced rainfall pattern that has the peak at the beginning of the pattern resulting in faster FS reduction at the beginning of the rainfall. As for the $60^{\circ}$ angle, the least FS is achieved at delayed rainfall due to insufficient time for water to infiltrate the slope and recover the FS before the rainfall stops, which give the least FS at delayed pattern rather than at the advanced and normal pattern.

As a comparison from [2], the least FS for LC is at $30^{\circ}$ slope angle at advanced rainfall pattern on the $96-\mathrm{hr}$ with $40-45 \%$ reduction and $450 \mathrm{~mm}$ rainfall for 120 hours while this research only has $225 \mathrm{~mm}$ rainfall for 120 hours with the least FS is at advanced pattern at $\mathrm{t}=$ $120-\mathrm{hr}$ and reduction of $1.29 \%$. The difference between the previous study with this study is the FS reduction percentage which is caused by the different rainfall intensity for the two studies.
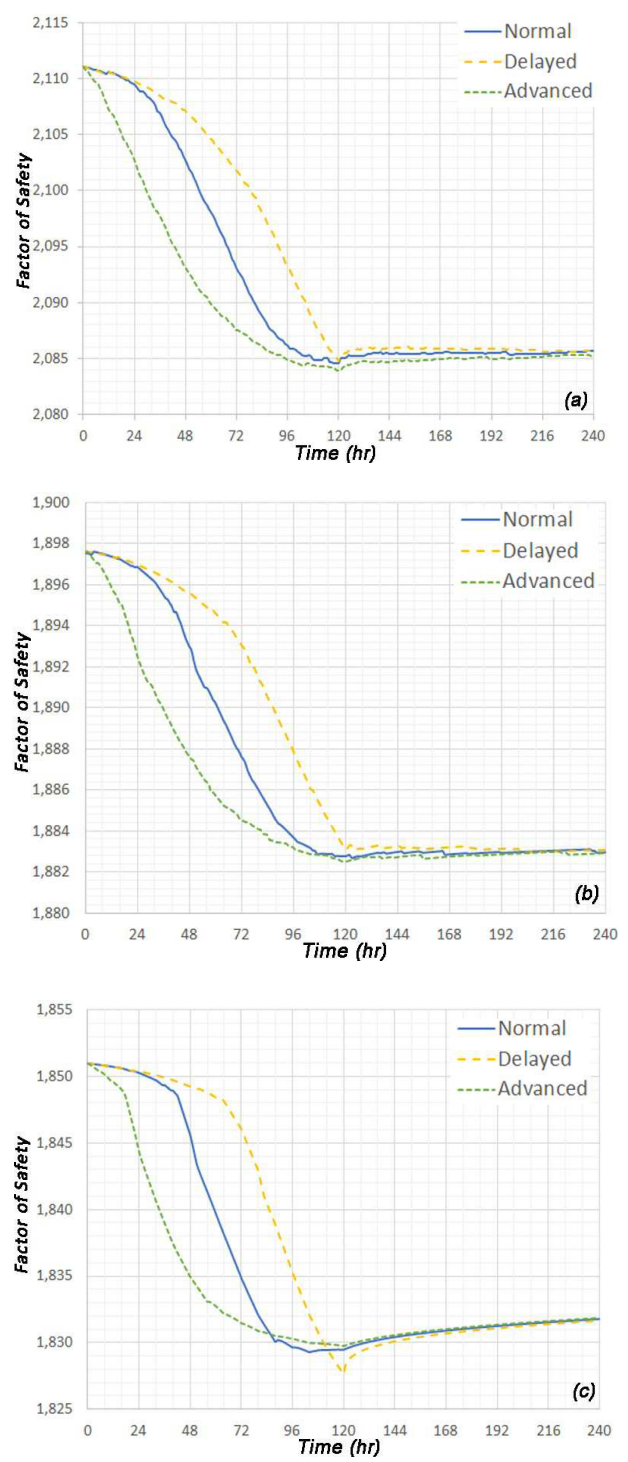

Fig. 6. FS vs time graph on different rainfall pattern for (a) $30^{\circ}$, (b) $45^{\circ}$, and (c) $60^{\circ}$

\subsection{The effect of different slope angles to FS for different rainfall patterns}

The comparison between FS and time for different slope angles and different rainfall pattern were observed with normalized FS. The normalized FS is used to see the different behaviour for each slope angle at a certain rainfall pattern at the same initial value. The results are shown in Fig. 7. 
From Fig. 7, it is shown that the largest FS reduction for each rainfall pattern is achieved at $30^{\circ}$ angle, followed by $60^{\circ}$, and the least is $45^{\circ}$. The behaviour that is shown on the three figures are likely because the steeper the slope, the less water will be infiltrated and the rest will turn into runoff $[6,15]$.
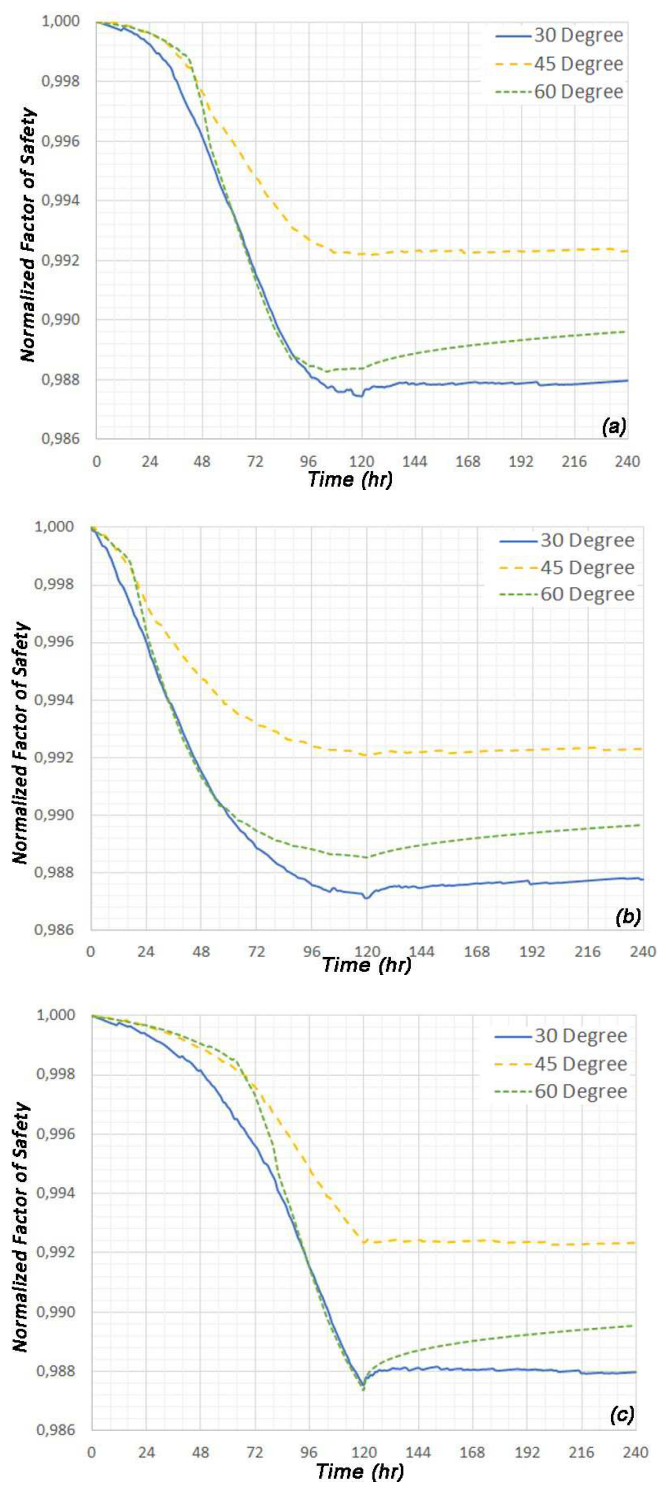

Fig. 7. Normalized FS vs time for (a) Normal, (b) Advanced, and (c) Delayed pattern

The $30^{\circ}$ angle slope has a smoother FS reduction pattern compared to the ones from the $45^{\circ}$ and $60^{\circ}$ slopes. The $45^{\circ}$ and $60^{\circ}$ slopes have a similar slower FS reduction at the beginning of the rainfall, while the $60^{\circ}$ slope FS will drastically decreased after that, following the pattern of FS from the $30^{\circ}$ angle slope. Considering the slope model in the 2D finite element, it is suspected that the extended horizontal surface behind the $60^{\circ}$ slope is allowing the rainfall infiltration like the gentle slope surface as in the $30^{\circ}$ slope model (see Fig.3.).

As for the redistribution step, for the three rainfall patterns, the change of FS for $60^{\circ}$ angle is much more significant than the two other angles because of the less infiltrated water is not much affecting the redistribution process.

\subsection{The effect of different hydraulic conductivity to FS for each slope angles}

From the comparison between FS's with different slope angles, it is known that the increase of FS on redistribution step is not significant with the applied hydraulic conductivity. To know whether different hydraulic conductivity affect the change of FS on normal rainfall pattern at $30^{\circ}$ slope angle, there will be three different hydraulic conductivities used in this section. The three different hydraulic conductivities noted as Initial $\left(1 \times 10^{-6} \mathrm{~m} / \mathrm{s}\right)$ which represents the hydraulic conductivity used on the beginning of this study, Low $\left(1 \times 10^{-7} \mathrm{~m} / \mathrm{s}\right)$, and High $\left(1 \times 10^{-5} \mathrm{~m} / \mathrm{s}\right)$. The Initial conductivity represent the value in between the Low and High conductivities. The results are shown in Fig.8.
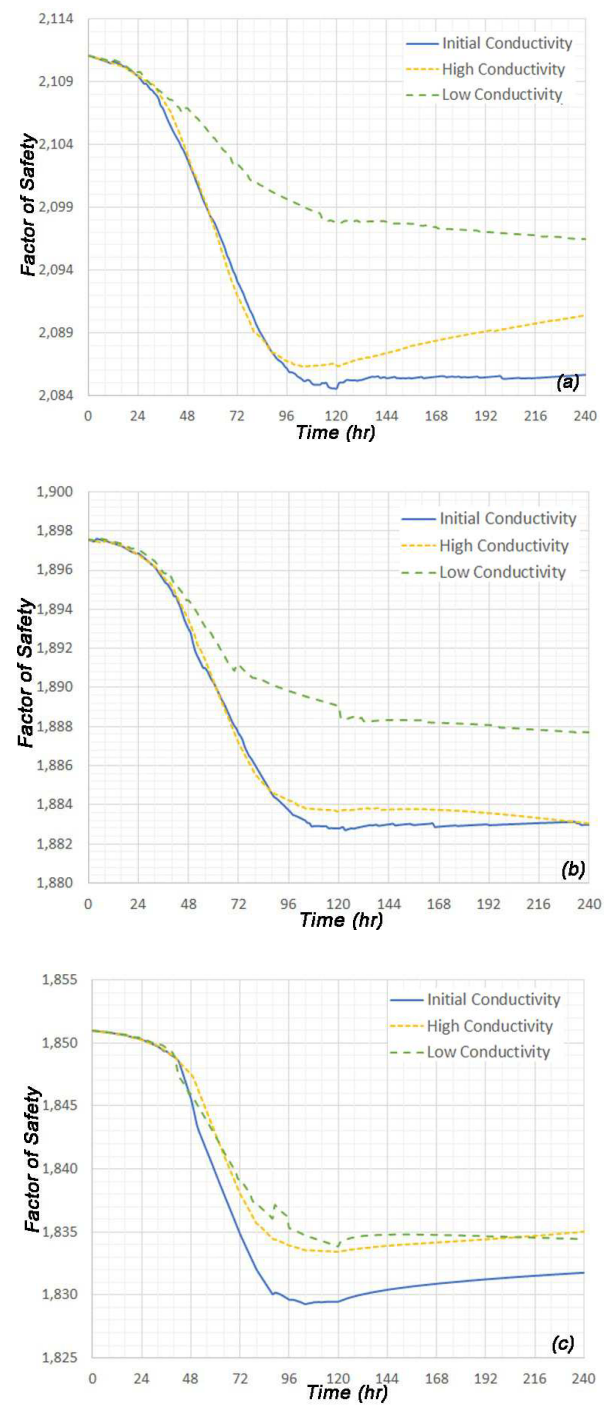

Fig. 8. FS vs Time on different hydraulic conductivity for (a) $30^{\circ}$, (b) $45^{\circ}$, and (c) $60^{\circ}$

From Fig.8, it is shown that for the three slope angles, $30^{\circ}, 45^{\circ}$, and $60^{\circ}$, the Low conductivity always gives the least FS reduction. The largest difference of FS 
reduction between the Low conductivity and the Initial or High conductivities is shown at the $30^{\circ}$ slope. This means that the effect of infiltration is significant to the reduction of FS since the low conductivities slowing down the infiltration of rainfall through the slope.

Compared to [2] at $30^{\circ}$ slope angles for different hydraulic conductivity, which is High $\left(1 \times 10^{-5} \mathrm{~m} / \mathrm{s}\right)$ and Low $\left(1 \times 10^{-6} \mathrm{~m} / \mathrm{s}\right)$, it is known that the least reduction of FS is obtained at High. As for this research, the same behaviour corresponds at Initial $\left(1 \times 10^{-6} \mathrm{~m} / \mathrm{s}\right)$ and High $\left(1 \times 10^{-5} \mathrm{~m} / \mathrm{s}\right)$ for the normal rainfall pattern.

\subsection{The change of pore water pressure during the rainfall}

There are two cross sections observed for pore water pressure profiles (Fig.5), which are 3-8 near the top of the slope and 10-9 near the toe of the slope. Both pore water pressure profiles are observed to see the behaviour of changing pore water pressure profile and rising ground-water level due to the two scenarios.

For the first scenario, the changing pore water pressure (PWP) are observed for different slope angles at each of the rainfall pattern. The results shown that the behaviour of different slope angles for every rainfall pattern is similar, as an example, the results for the changing PWP at advanced rainfall pattern are shown in Fig.9 (Section 3-8) and Fig.10 (Section 9-10).

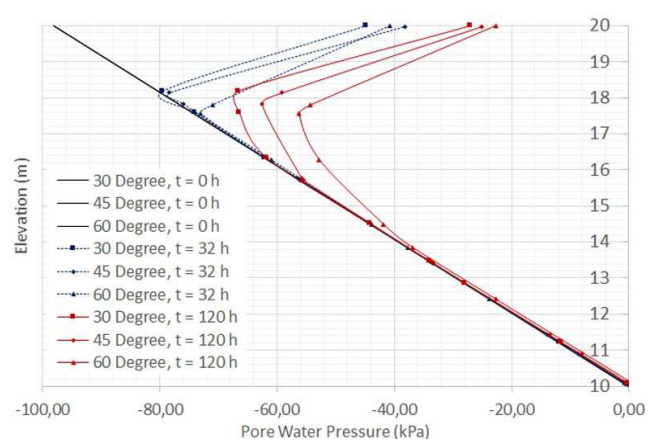

Fig. 9. PWP profile change during advanced rainfall pattern at section 3-8

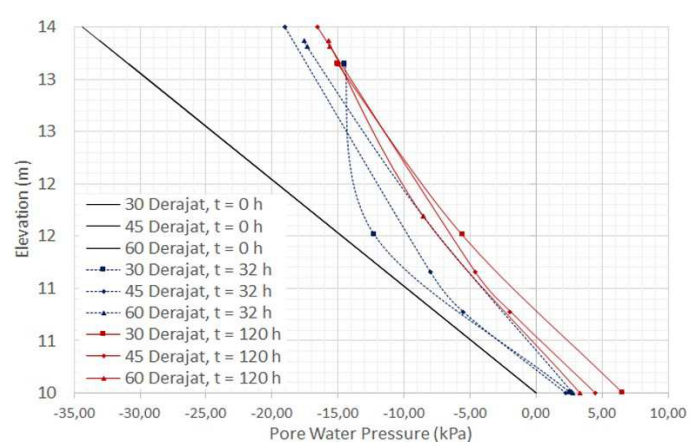

Fig. 10. PWP profile change during advanced rainfall pattern at section 9-10

From Fig.9 and Fig.10, it is shown that the PWP increases as the duration of the rainfall increase which means that the rainfall is infiltrated into the slope and lowered the FS. This behaviour corresponds to the behaviour shown in Fig.7 which shows that the least FS is at the end of the rainfall.

From Fig.9, at a position near the top, the $60^{\circ}$ slope has the least value of negative PWP than the two other angles which indicates that the slope will have the least FS value. This behaviour corresponds for the initial FS of the three angles where the $60^{\circ}$ slope angle have the least initial FS than the two others. While from Fig.10, at a position near the toe, the $30^{\circ}$ slope has the biggest value of positive PWP than the two other angles which indicates the greatest rise of the ground-water level due to rainfall infiltration. The behaviour of rising of groundwater level at the $30^{\circ}$ slope corresponds to the behaviour where $30^{\circ}$ slope have the greatest FS reduction.

Compared to [2], for $30^{\circ}$ slope LC soil, the increased value of PWP for every rainfall is the same even if at different time. At this research, the increased value of PWP is not the same but are achieved at the end of the rainfall. Even though the value is different, both research exhibits the same behaviour.

At the second scenario, the PWP profile at every angle is observed with different hydraulic conductivity. The behaviour of every angle is similar, as an example, the $30^{\circ}$ PWP Profile at normal rainfall is shown in Fig. 12 (Section 3-8) and Fig.13 (Section 9-10).

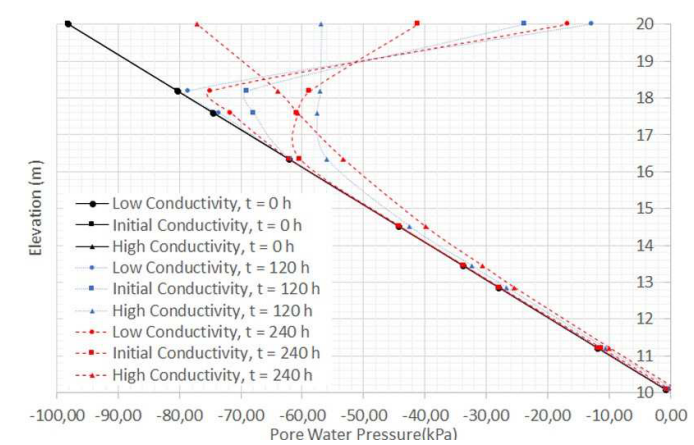

Fig. 11. PWP profile change for normal rainfall for $30^{\circ}$ slope at section 3-8

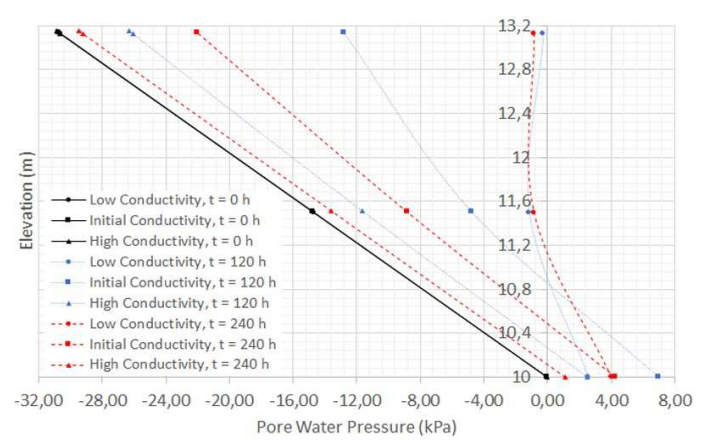

Fig. 12. PWP profile change for normal rainfall for $30^{\circ}$ slope at section 9-10

From Fig.11 and Fig.12, it is shown at the end of the rainfall, the greatest PWP is achieved at Low Conductivity PWP near the top while the greatest PWP near the toe is achieved at Initial Conductivity. But, at elevation of $18-\mathrm{m}$, inside the slope's body, the Low Conductivity PWP is the lowest than the other 
conductivity which leads to higher FS. This corresponds to the behaviour of which the Low Conductivity FS redistribution step, the Low Conductivity's PWP is greater than the other conductivity which corresponds to the behaviour of which the FS at redistribution keeps decreasing due to the slow infiltration rate.

From Fig.11 and Fig.12, it is also shown that the PWP for High Conductivity is the smallest and at the end of the distribution step, the PWP decreases which leads to the behaviour of increasing FS at the end of the redistribution and great infiltration rate.

\section{Conclusion}

This study tries to analyse the effect of different rainfall pattern to FS value of slope. The effect of the slope's angle and hydraulic conductivity also being observed. The following conclusions can be drawn from this study:

The steeper the slope, the smaller the initial FS of the slope. When rainfall occurs, FS reduction in gentle slope is found to be higher than the FS reduction in steep slope at any type of rainfall pattern. Gentle slope tends to have the least FS after advanced rainfall pattern while steep slopes have the least FS after delayed rainfall pattern.

The FS reduction is mainly caused by the rising of the ground-water level during rainfall which builds positive PWP for the slope.

The higher the hydraulic conductivity, the smaller the FS reduction during the rainfall and the greater the increase of FS during redistribution which is caused by the infiltration rate of the hydraulic conductivity that enable the PWP that rises during the rainfall to decrease after the redistribution.

Some factors related to the slope model in 2D finite element may contribute to the results of this study, such as the effect of horizontal surface behind the slope. This issue should be considered for the next study.

The authors would like to thank Civil Engineering Department, Universitas Indonesia, especially Soil Mechanic Laboratory staffs and lecturers for the spirit and input of this research. reduction is the smallest. But, at the end of the

\section{References}

1. H. Rahardjo, T.H. Ong, R.B. Rezaur, E.C. Leong, J. Geotech. Geoenv. Eng., 133:12, 1532-1543 (2007)

2. A. Rahimi, H. Rahardjo, E.C. Leong, J. Geotech. Geoenv. Eng., 137:5, 483-491 (2011)

3. T.T. Lim, H. Rahardjo, M.F. Chang, D.G. Fredlund, Can. Geotech. J., 33(4), 618-628 (1996)

4. J.M. Duncan, S.G. Wright, Soil Strength and Slope Stability. (John Wiley \& Sons, Inc, 2005)

5. F. Silva, W. Lambert, W.A. Marr, J. Geotech. \& Geoenv. Eng. V 134, 12 (2008)

6. B.B.K. Huat, F.HJ. Ali, T.H. Low, Geotech. \& Geo. Eng. V 24 1293-1306 (2006)

7. D.G. Fredlund, The emergence of unsaturated soil mechanics (Fourth Spencer J. Buchanan Lecture, Texas A\&M, 1996).

8. D.G. Fredlund, H. Rahardjo, M.D. Fredlund, Unsaturated Soil Mechanics in Engineering Practice. (John Wiley \& Sons Inc, 2012)

9. D.G. Fredlund, J. Geotech. Geoenv. Eng., 132:3, 286-321 (2006)

10. D.G. Fredlund, A. Xing, Can. Geotech. J., 31(4), 521-532 (1994).

11. D.M. Gray, D.I. Norum, Proceedings of Hydrology Symposium, No.6 (1967)

12. H.F. Yeh, C.C. Lee, C.H. Lee, J. Environ. Eng. Manage. 18(4), 261-268 (2008)

13. M. Budhu, Soil Mechanics and Foundations (John Wiley \& Sons Inc, 2011)

14. B. Look, Handbook of Geotechnical Investigation and Design Tables (Taylor \& Francis, 2007)

15. M.P. Purba, Besar Aliran Permukaan (Run-off) pada Berbagai Tipe Kelerengan dibawah Tegakan Eucalyptus spp. (Studi Kasus di HPHTI PT. Toba Pulp Lestasi, Tbk. Sektor Aek Nauli) (Universitas Sumatera Utara, 2009) 